\title{
Propriedades das argamassas de revestimento contendo resíduo proveniente da produção do $\mathrm{TiO}_{2}(\mathrm{MNR})$
}

\section{(Properties of coating mortars with waste from $\mathrm{TiO}_{2}$ production - UOW)}

\author{
D. D. M. de Albuquerque ${ }^{1}$,J.S. Andrade Neto ${ }^{1 *}$, N. S. de Amorim Júnior ${ }^{1}$, D. V. Ribeiro ${ }^{1}$ \\ ${ }^{1}$ Universidade Federal da Bahia, Laboratório de Ensaios em Durabilidade dos Materiais, R. Aristides Novis 2, \\ 40210-630, Salvador, BA, Brasil
}

\begin{abstract}
Resumo
Nesse trabalho avaliou-se a influência da adição do resíduo da produção de $\mathrm{TiO}_{2}$, minério não reagido (MNR), nas propriedades de argamassas de revestimento. Para isso, avaliaram-se as propriedades de argamassas mistas (cimento Portland branco e cal) com adições de $0 \%, 5 \%, 10 \%$ e $15 \%$ de MNR, em relação à massa do cimento. As argamassas foram avaliadas quanto ao tempo de pega, reologia (flow table, squeeze flow e reometria) e propriedades físicomecânicas, além de ensaios de aderência à tração e pipeta de Karsten. Os resultados obtidos indicaram retardo na pega e perda de plasticidade com a incorporação do MNR. Ademais, o resíduo não influenciou de forma significativa as propriedades físico-mecânicas das argamassas. Concluiu-se que o MNR pode ser incorporado às argamassas de revestimento, apresentando propriedades dentro dos requisitos normativos. Contudo, para a viabilização da utilização do MNR em argamassas, ressalta-se a necessidade de estudos de lixiviação, solubilização e de durabilidade dessas argamassas.
\end{abstract}

Palavras-chave: argamassas de revestimento, resíduos industriais, minério não reagido (MNR), reologia.

\begin{abstract}
In this study, the influence of the addition of waste from $\mathrm{TiO}_{2}$ production, unreacted ore waste (UOW), in the properties of coating mortars was evaluated. The properties of white Portland cement-lime mortars with 0\%, 5\%, 10\% and $15 \%$ UOW additions were evaluated in relation to the cement weight. Mortars were evaluated for setting time, rheology (flow table, squeeze flow and rheometry), physical-mechanical properties, adherence to traction and Karsten pipette. The results indicated a delay in the setting time and a loss of plasticity with the incorporation of the UOW. In addition, it was observed that the waste did not significantly influence the physical and mechanical properties of the mortars. The UOW can be incorporated into the coating mortars, presenting properties within the normative requirements. However, for a complete analysis of the feasibility of the use of UOW in mortars, it is necessary to study leaching, solubilization and durability of the mortars.
\end{abstract}

Keywords: coating mortars, industrial waste, unreacted ore waste (UOW), rheology.

\section{INTRODUÇÃO}

Considerada um dos grandes problemas contemporâneos, a elevada quantidade de resíduos gerados pela atividade humana se intensificou com a sistematização dos processos produtivos desde as Revoluções Industriais, exigindo esforços multidisciplinares para encontrar alternativas técnica e economicamente viáveis para a reutilização desses rejeitos. Com o aumento da produção, as indústrias vêm emitindo uma crescente quantidade de agentes poluentes, sejam eles gasosos ou sólidos, e que se tornam um sério problema ambiental devido à sua inadequada disposição.

*josedasilvaandradeneto@gmail.com

(D) https://orcid.org/0000-0001-9655-2659
Sendo assim, pesquisas que visem um viável aproveitamento desses resíduos são de grande valia. Segundo dados da ABETRE (Associação Brasileira de Empresas de Tratamento de Resíduos) [1], o Brasil gerou no ano de 2016, 33 milhões de toneladas de resíduos industriais, dos quais 25 milhões de toneladas não têm tratamento adequado, gerando um custo de $\mathrm{R} \$ 600$ milhões por ano ao governo. A indústria da construção civil tem potencial para absorver uma grande parte dos resíduos sólidos industriais, através da incorporação desses resíduos nos materiais e elementos de construção [2]. As matrizes cimentícias são alcalinas e geralmente são usadas no acondicionamento de resíduos por serem conhecidas, baratas e de acessível tecnologia. Sua elevada alcalinidade inibe processos microbiológicos e podem incorporar resíduos líquidos e pastosos, por 
necessitarem de água para hidratação, além disso, reduz a solubilidade de muitos resíduos orgânicos tóxicos e perigosos [3].

Diversos estudos abordam a viabilidade da utilização de adições de diferentes resíduos na produção de argamassas [4-7]. Estes resíduos apresentam contribuições significativas relacionadas à trabalhabilidade, deformação, resistência e permeabilidade das argamassas, além de contribuir com princípios relacionados à sustentabilidade ambiental na reciclagem de resíduos, redução de emissão de poluentes e diminuição do consumo de matérias-primas [4]. No entanto, poucos estudos foram desenvolvidos utilizando resíduos provenientes da produção de $\mathrm{TiO}_{2}$, tendo destaque a verificação do comportamento fotocatalítico em argamassas por meio da degradação de compostos orgânicos (azul de metileno) [8], efeito na hidratação de argamassas por análise de DRX [9], além dos estudos [10, 11] que utilizaram resíduo de $\mathrm{TiO}_{2}$ como material fundente para produção de clínquer Portland. O minério não reagido (MNR) utilizado nesta pesquisa, é um resíduo industrial gerado na produção do dióxido de titânio pela rota sulfato na unidade da Cristal Pigmentos do Brasil (Camaçari/BA) que produz cerca de 60 mil toneladas de $\mathrm{TiO}_{2}$ anualmente, gerando cerca de 30 mil toneladas do resíduo. Este resíduo ainda não está inserido em um plano efetivo de reutilização e/ou reciclagem, sendo atualmente disposto em aterro controlado, o que representa um elevado gasto para a empresa geradora. Albuquerque et al. [12] avaliaram os efeitos da adição do MNR, proveniente da produção de $\mathrm{TiO}_{2}$ rota sulfato, nas propriedades do estado endurecido e aplicado. Os autores observaram que a adição de até $15 \%$ do resíduo não influenciou significativamente nas propriedades físico-mecânicas das argamassas, sendo possível, assim, reduzir o consumo de cimento e reutilizar o MNR.

Apesar da utilização de MNR em argamassas ser promissora, para viabilizar a sua utilização são necessários estudos sobre a influência do resíduo nas demais propriedades da argamassa, como hidratação e reologia. Assim, este trabalho tem o potencial de prestar contribuição científica no sentido de caracterizar e avaliar o efeito da adição de um resíduo pouco conhecido e pouco estudado em argamassas de revestimento, por meio de análises de hidratação, reologia e nos estados endurecido (resistências à tração na flexão e à compressão axial, módulo de elasticidade dinâmico, porosidade e densidade aparentes) e aplicado (resistência de aderência à tração e absorção pela pipeta de
Karsten). Além disso, as delimitações ainda existentes pela baixa produção científica sobre a destinação sustentável do MNR, bem como a disposição em aterro industrial sem nenhuma política de reuso ou reciclagem de forma efetiva, comprovam a necessidade de estudos aprofundados a respeito do aproveitamento deste resíduo.

\section{MATERIAIS E MÉTODOS}

Materiais: para a produção das argamassas utilizaramse cimento Portland branco, cal hidratada (CH-II), areia proveniente da jazida localizada no município de CamaçariBahia, minério não reagido (MNR), resíduo proveniente da produção do $\mathrm{TiO}_{2}$, fornecido pela Cristal Pigmentos do Brasil, localizada no município de Camaçari-BA, e água potável. O MNR foi coletado conforme metodologia de amostragem de resíduos especificada na NBR 10007:2004 [13]. Foi observado no momento das coletas que o resíduo apresentava granulometria irregular, com algumas impurezas e contaminação superficial. Para a caracterização e utilização do resíduo foi realizado um beneficiamento por meio de secagem em estufa a $105 \pm 5{ }^{\circ} \mathrm{C}$ por $24 \mathrm{~h}$. Em seguida, foi realizado um procedimento de moagem em moinho rotativo horizontal (Quimis, Q298), com volume de jarra de $16055 \mathrm{~cm}^{3}$, contendo 30 bolas cerâmicas com diâmetro de $4 \mathrm{~cm}$ e $2,5 \mathrm{~kg}\left(2941 \mathrm{~cm}^{3}\right)$ do resíduo, por 30 $\mathrm{min}$. Por fim, peneiramento em peneira de abertura de malha de $600 \mu \mathrm{m}$, que apresentou uma eficiência de 98\%, tendo sido essa a condicionante para a utilização do material.

Caracterização das matérias-primas: inicialmente foram realizados os ensaios para a caracterização das matériasprimas quanto às suas propriedades físicas e químicas. Para a caracterização física do cimento Portland branco, da cal hidratada e do MNR, foram realizados ensaios de picnometria a gás hélio (Micromeritics, AccuPyc II 1340), área superficial Blaine (Acmel, BSA1) e distribuição do tamanho de partículas por granulometria a laser (Cilas, 1180). Já para a areia, determinou-se a distribuição granulométrica, o módulo de finura e a dimensão máxima característica por peneiramento mecânico, conforme método descrito na NBR NM 248:2003 [14]. A massa específica da areia foi determinada pelo método de Chapman, de acordo com a NBR 9776:1987 [15]. A composição química do MNR, na forma de óxidos, foi determinada por espectroscopia de fluorescência de raios X(FRX), por meio do equipamento $\mathrm{S} 2$ Ranger da Bruker. Já para a identificação de sua composição

Tabela I - Consumo de matérias-primas para a produção de um metro cúbico de argamassa.

[Table I - Consumption of raw materials for the production of one cubic meter of mortar.]

\begin{tabular}{cccccc}
\hline Traço & Cimento $(\mathrm{kg})$ & Cal $(\mathrm{kg})$ & Areia $(\mathrm{kg})$ & Água $(\mathrm{kg})$ & MNR $(\mathrm{kg})$ \\
\hline REF & 255,28 & 255,28 & 1276,42 & 331,87 & 0,00 \\
$5 \%$ MNR & 254,22 & 254,22 & 1271,12 & 330,49 & 12,71 \\
$10 \%$ MNR & 253,17 & 253,17 & 1265,86 & 329,12 & 25,32 \\
$15 \%$ MNR & 252,13 & 252,13 & 1260,65 & 327,77 & 37,82 \\
\hline
\end{tabular}


mineralógica, utilizou-se a técnica de difração de raios $\mathrm{X}$ (DRX). Para tal, foi utilizado um difratômetro (Bruker, D2 Phaser) com tubo de alvo de cobre (radiação K $\alpha$ com comprimento de onda de 1,54060 ̊) em $30 \mathrm{kV}$ e $10 \mathrm{~mA}$, sem sistema de filtragem com monocromador secundário. Os difratogramas foram obtidos na faixa de $2 \theta$ de $5^{\circ}$ a $90^{\circ}$, utilizando a varredura em modo contínuo a $0,002 \%$ para todas as análises. As fases presentes nas amostras foram posteriormente identificadas com o auxílio do programa Diffrac plus-EVA, com base de dados do sistema COD (Crystallography Open Database), e quantificadas através do método de Rietveld, com a utilização do programa TOPAS e dos arquivos CIF (Crystallographic Information File).

Dosagem e moldagem das argamassas: as argamassas de revestimento foram confeccionadas com traço de 1:1:5:1,3 (cimento Portland branco: cal hidratada: areia: água) em massa, definido por meio do método de Selmo [16], além das adições de 5\%,10\% e 15\% de MNR, em relação à massa do cimento. A Tabela I apresenta o consumo de material por metro cúbico de argamassa produzido. A adição do resíduo reduziu a quantidade utilizada de cimento, cal, areia e água. Com a redução da quantidade necessária das demais matériasprimas, principalmente o cimento, podem ser alcançados benefícios econômicos e ambientais. Posteriormente, as argamassas foram misturadas em uma argamassadeira de bancada, tipo planetária, de acordo com procedimento preconizado pela NBR 13276:2005 [17].

Caracterização das pastas: o tempo de pega das pastas foi determinado pelo método de Vicat, de acordo com a NBR 16607:2017 [18]. Para tal, foram moldadas pastas

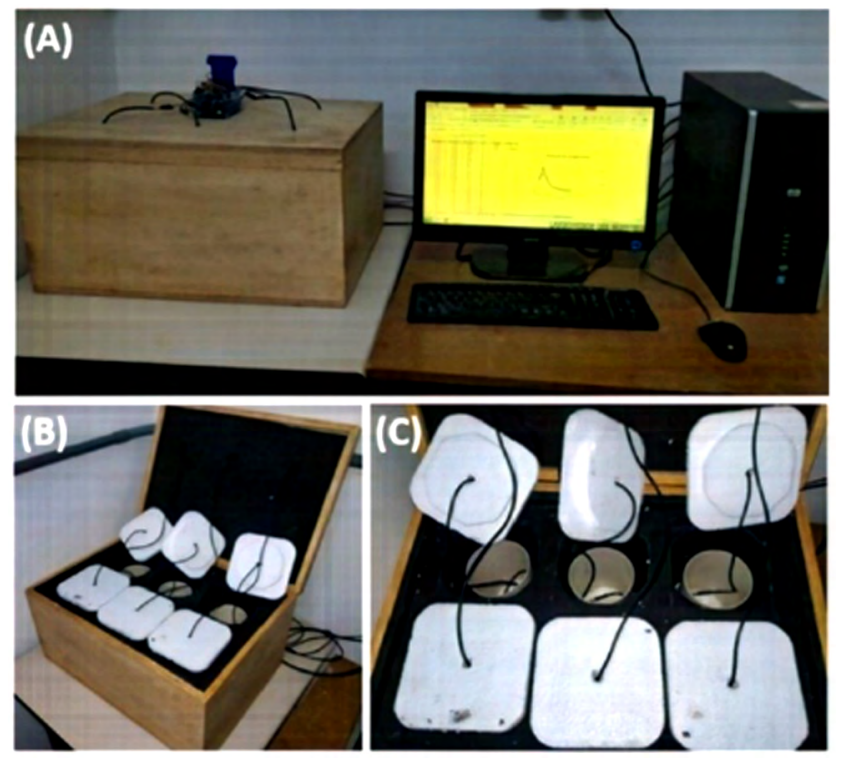

Figura 1: Calorímetro utilizado para obter as curvas de temperatura durante o processo de hidratação: A) conexão e monitoramento das medidas; B) configuração interna do calorímetro; e C) localização dos sensores de temperatura no interior do equipamento.

[Figure 1: Calorimeter used to obtain the temperature curves during the hydration process: A) connection and monitoring of measures; B) internal configuration of the calorimeter; and $C$ ) location of the temperature sensors inside the equipment.] com 'consistência normal' e foi utilizado o equipamento de Vicat automático Solotest, sendo o ensaio realizado 3 vezes para cada traço. Para melhor entender o efeito da adição do MNR no processo de hidratação do cimento, a temperatura das pastas com o decorrer do processo de hidratação foi acompanhada por meio de um calorímetro semiadiabático, desenvolvido no LEDMa/UFBA (Fig. 1). Neste ensaio, as pastas com diferentes adições de MNR foram inseridas em compartimentos com isolamento térmico, onde sensores digitais de temperatura DS18B20 monitoraram constantemente a temperatura da mistura. Os dados foram então exportados para um computador através do Arduino UNO, sendo o tratamento dos dados realizado no Excel. Foram analisadas 3 amostras por mistura, sendo apresentado o valor médio, uma vez que os resultados foram semelhantes.

Caracterização das argamassas no estado fresco: foram determinados os índices de consistência (flow table) das argamassas de acordo com os procedimentos descritos na NBR 13276:2005 [17]. Para isto utilizou-se uma mesa de consistência automática (Contenco, I-3019-B). Como o ensaio de flow table é um ensaio monoponto, insuficiente para descrever o comportamento reológico complexo das argamassas $[19,20]$, foram realizados também os ensaios de squeeze flow e reometria rotacional. O ensaio de squeeze flow foi realizado nas argamassas após $15 \mathrm{~min}$ de mistura com velocidade de deslocamento de $0,1 \mathrm{~mm} / \mathrm{s}$ em uma máquina universal de ensaios Instron, com controle de deslocamento e célula de carga de $2 \mathrm{kN}$. Os ensaios foram realizados de acordo com o método descrito na NBR 15839:2010 [21]. Para o ensaio de reometria rotacional, em que foi avaliado o comportamento reológico, utilizou-se um reômetro rotacional (Rheotest Medingen, $\mathrm{RN}$ 4.1) e uma rotina de ensaio adaptada de [22], apresentada na Fig. 2. Para os procedimentos citados, os ensaios foram repetidos 3 vezes a fim de se garantir confiabilidade no resultado.

Os parâmetros reológicos foram obtidos aplicandose o modelo de Herschel-Bulkley (Eq. A) na curva de desaceleração das paletas no primeiro ciclo de cisalhamento aos 2 min, conforme [23-25]. Já a viscosidade plástica foi determinada de acordo com a Eq. B:

$$
\mathrm{T}=\mathrm{a}+\mathrm{b} \cdot \mathrm{N}^{\mathrm{c}}
$$

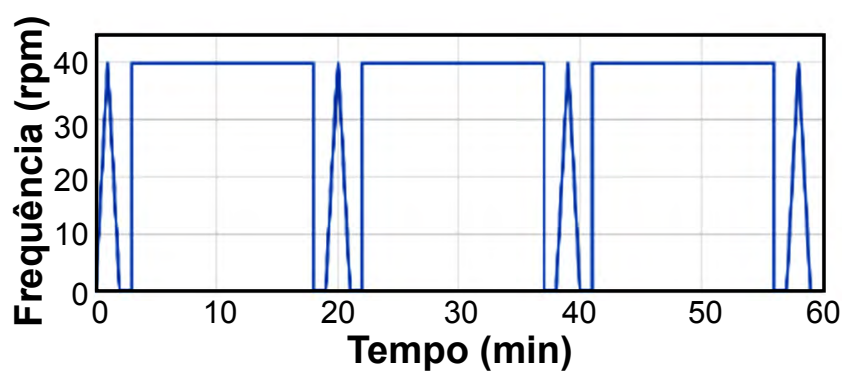

Figura 2: Configuração de ensaio de reometria rotacional adotada com base na frequência de rotação em função do tempo de ensaio (adaptado de [22]).

[Figure 2: Configuration of the rotational rheometry test adopted based on the rotation frequency versus the test time (adapted from [22]).] 


$$
\eta_{\mathrm{pl}}=\mathrm{b} \cdot\left(\dot{\mathrm{y}}_{\text {máx }}\right)^{\mathrm{c}-1}
$$

em que $\mathrm{T}$ é o torque medido pelo reômetro, $\mathrm{N}$ é a frequência de rotação das paletas, a é a tensão de escoamento, b é o índice de consistência, c é o índice de comportamento, que indica o comportamento reológico do material [dilatante $(c<1)$, de Bingham $(c=1)$ ou pseudoplástico $(c>1)], \eta_{p 1}$ é a viscosidade plástica e $\dot{y}_{\max }$ é a taxa máxima de cisalhamento aplicada.

Caracterização das argamassas no estado endurecido: para a caracterização da argamassa no estado endurecido, foram moldados 9 corpos de prova prismáticos $(4 \times 4 \times 16 \mathrm{~cm})$ para cada mistura, sendo utilizados 3 corpos de prova de cada idade para a determinação da resistência à tração na flexão e 6 para a determinação da resistência à compressão axial. A desmoldagem dos corpos de prova foi realizada em $24 \mathrm{~h}$ sendo estes, em seguida, imersos em água saturada com cal. A cura imersa se manteve até o momento da realização dos ensaios. Foram realizados ensaios de determinação da resistência à tração na flexão e à compressão axial nas argamassas, aos 3, 7 e 28 dias, seguindo procedimento descrito na NBR 13279:2005 [26]. Para tal, foi utilizada uma prensa servocontrolada (Contenco, HD-120T), com capacidade de 120 tf. Para se determinar a porosidade e densidade aparentes das amostras de argamassas foram utilizados 3 corpos de prova para cada traço, sendo ensaiados aos 28 dias, de acordo com o método descrito na NBR 9778:2005 [27]. Já o módulo de elasticidade dinâmico aos 28 dias foi determinado por meio do equipamento emissor de ondas ultrassônicas (Proceq, PunditLAB+), de acordo com procedimento descrito na NBR 15630:2008 [28], utilizandose 3 corpos de prova de cada mistura.

Caracterização das argamassas no estado aplicado: para avaliação da influência da adição do MNR no estado aplicado das argamassas, foram construídos painéis de alvenaria com dimensões de $60 \times 60 \mathrm{~cm}$; em seguida foi aplicada a camada de chapisco de traço 1:3 (cimento:areia), sendo curada por 3 dias com aspersão de água. Em seguida, foram aplicados os revestimentos contendo diferentes teores de MNR, além da argamassa de referência, com espessura média de $30 \mathrm{~mm}$, sendo curados por 7 dias com aspersão de água. A construção dos painéis e a execução do revestimento foram realizadas por um profissional da construção civil, a fim de melhor simular as condições de aplicação. Para determinar as resistências de aderência à tração aos 28 dias foi utilizado o procedimento descrito na NBR 13528:2010 [29], sendo realizado o ensaio em 12 corpos de prova de cada traço. Já para avaliar a absorção/permeabilidade à água das argamassas aos 72 dias, foi utilizada a pipeta de Karsten, em um método também conhecido como 'método do cachimbo', proposto pelo Centre Scientifique et Technique de la Construction (CSTC) da Bélgica (CSTC/NIT-140, 1982), sendo o ensaio realizado por 3 vezes para cada traço.

Análise estatística dos resultados: os resultados de tempo de pega, índice de consistência (flow table) e todos os resultados de caracterização do estado endurecido e aplicado foram analisados estatisticamente por meio da análise de variância dos dados (ANOVA) de fator único utilizando um nível de significância $(\alpha)$ de 0,05 .

\section{RESULTADOS E DISCUSSÃO}

Caracterização das matérias-primas: a Tabela II apresenta os resultados da caracterização física e a Fig. 3 apresenta as curvas de distribuição do tamanho de partículas das matérias-primas. Os resultados obtidos evidenciaram a elevada finura do MNR, que apresentou uma curva de distribuição de partículas intermediária à curva do cimento e da cal. De acordo com o resultado de caracterização química do MNR (Tabela III), foi verificado, conforme esperado, um alto teor de dióxido de titânio, que é justificado em virtude da utilização das matérias-primas (ilmenita e escória de titânio). Já o óxido de cálcio $(\mathrm{CaO})$ e o trióxido de enxofre $\left(\mathrm{SO}_{3}\right)$ foram provenientes de etapas do processo de geração do MNR (neutralização e sulfatação, respectivamente). $\mathrm{O}$ óxido de ferro $\left(\mathrm{Fe}_{2} \mathrm{O}_{3}\right)$ encontrado foi proveniente da oxidação do ferro presente na ilmenita. A sílica $\left(\mathrm{SiO}_{2}\right)$ pode ser proveniente de contaminação com areia no momento da coleta e/ou armazenamento do resíduo. Os demais compostos foram provavelmente associados às impurezas contidas no MNR.

A Fig. 4 apresenta o difratograma de raios $X$ do minério não reagido (MNR) com a identificação de fases cristalinas. Observou-se a presença de picos das fases cristalinas do dióxido de titânio nas formas anatásio $\left(\mathrm{TiO}_{2}\right)$ e rutilo $\left(\mathrm{TiO}_{2}\right)$, oriundos da não dissolução da matéria-prima (ilmenita e escória de tiânio) no ácido sulfúrico, que é utilizado com o objetivo de extrair o titânio durante o processo de fabricação do pigmento. Já a anidrita $\left(\mathrm{CaSO}_{4}\right)$ provavelmente foi resultado de reações entre o ácido sulfúrico, utilizado

Tabela II - Propriedades físicas do cimento branco, cal, MNR e areia utilizados.

[Table II - Physical properties of the white Portland cement, hydrated lime, UOW and sand.]

\begin{tabular}{ccccc}
\hline Propriedade & Cimento branco & Cal & MNR & Areia \\
\hline Massa específica $\left(\mathrm{g} / \mathrm{cm}^{3}\right)$ & $3,05 \pm 0,01$ & $2,40 \pm 0,01$ & $3,06 \pm 0,01$ & $2,67 \pm 0,02$ \\
Área superficial Blaine $\left(\mathrm{cm}^{2} / \mathrm{g}\right)$ & $3715 \pm 39$ & $5304 \pm 205$ & $3681 \pm 481$ & - \\
Diâmetro médio $(\mu \mathrm{m})$ & 12 & 29 & 22 & 260 \\
Diâmetro máximo característico $(\mathrm{mm})$ & - & - & - & 1,18 \\
Módulo de finura & - & - & - & 1,32 \\
\hline
\end{tabular}




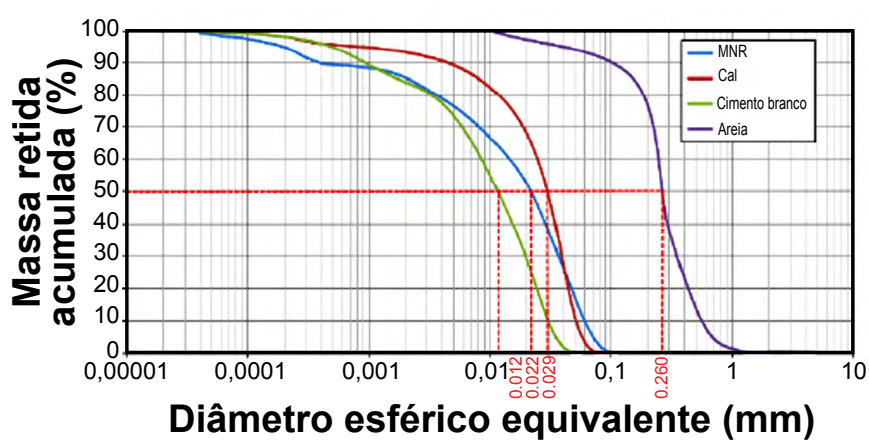

Figura 3: Curvas de distribuição do tamanho de partículas das matérias-primas.

[Figure 3: Particle size distribution curves of the raw materials.]

Tabela III - Composição química, em óxidos (\% em massa), do MNR, obtida por FRX.

[Table III - UOW chemical composition, in oxides (wt\%), obtain by XRF.]

\begin{tabular}{ccccccccc}
\hline $\mathrm{TiO}_{2}$ & $\mathrm{SiO}_{2}$ & $\mathrm{CaO}$ & $\mathrm{SO}_{3}$ & $\mathrm{Fe}_{2} \mathrm{O}_{3}$ & $\mathrm{Na}_{2} \mathrm{O}$ & $\mathrm{Al}_{2} \mathrm{O}_{3}$ & $\mathrm{MgO}$ & $\mathrm{ZrO}_{2}$ \\
\hline 43,40 & 14,70 & 13,20 & 10,00 & 7,61 & 3,04 & 2,56 & 1,49 & 1,47 \\
\hline
\end{tabular}

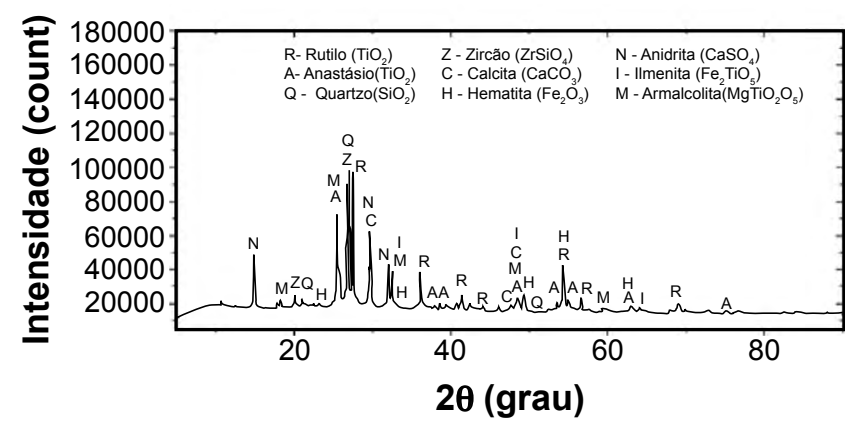

Figura 4: Difratograma de raios $X$ do minério não reagido.

[Figure 4: X-ray diffraction pattern of unreacted ore waste.]

na etapa de sulfatação, e do hidróxido de cálcio, que foi adicionado ao resíduo com o objetivo de neutralizar o seu $\mathrm{pH}$ e facilitar, assim, o seu descarte. A ilmenita $\left(\mathrm{Fe}_{2} \mathrm{TiO}_{5}\right)$ foi proveniente do minério ilmenita, a armalcolita $\left(\mathrm{MgTi}_{2} \mathrm{O}_{5}\right)$ pode estar associada à escória de titânio, a calcita $\left(\mathrm{CaCO}_{3}\right)$ provavelmente foi resultado da reação de carbonatação entre o hidróxido de cálcio $\left[\mathrm{Ca}(\mathrm{OH})_{2}\right]$ e o dióxido de carbono atmosférico $\left(\mathrm{CO}_{2}\right)$ e o quartzo $\left(\mathrm{SiO}_{2}\right)$, o zircão $\left(\mathrm{ZrSiO}_{4}\right)$ e

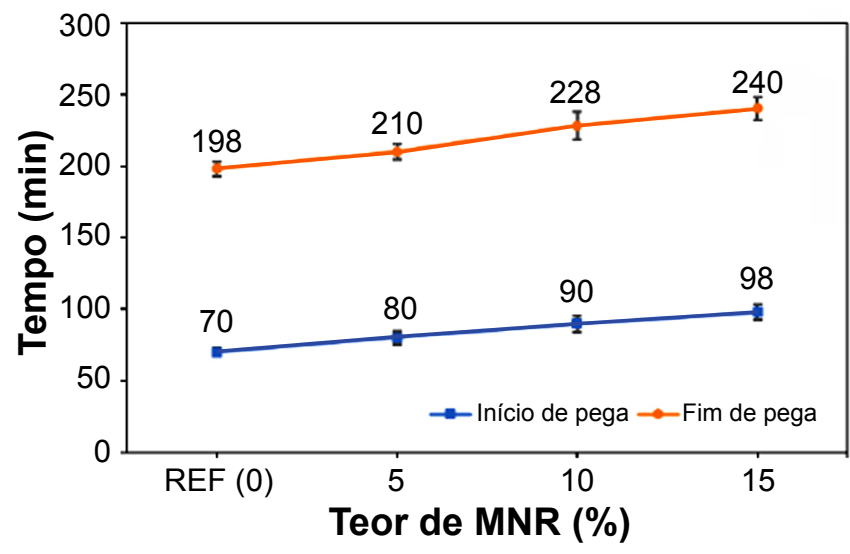

Figura 5: Tempos de início e fim de pega das pastas de cimento em função do teor de MNR adicionado.

[Figure 5: Initial and final setting time of the pastes with different UOW contents.]

a hematita $\left(\mathrm{Fe}_{2} \mathrm{O}_{3}\right)$ foram provenientes de impurezas nas matérias-primas.

Caracterização das pastas: na Fig. 5 são apresentados os resultados dos tempos de início e fim de pega das pastas com diferentes teores de MNR, determinados pelo método de Vicat. Já a análise ANOVA destes resultados é apresentada na Tabela IV. Observou-se um retardo crescente nos tempos de início e fim de pega com a adição do resíduo, com um aumento de cerca de $40 \%$ para as pastas contendo $15 \%$ de MNR, com diferença estatisticamente significante conforme análise apresentada na Tabela IV. O retardo nos tempos de início e fim de pega das argamassas com MNR foi, possivelmente, devido à presença da anidrita $\left(\mathrm{CaSO}_{4}\right)$ na composição do resíduo [30]. Além disso, a redução gradativa de cimento a partir da adição de MNR pode ter contribuído para o retardo observado.

O processo de hidratação do cimento Portland branco é exotérmico, sendo possível acompanhá-lo por meio de uma curva de evolução da temperatura em função do tempo. Como pode ser observado na Fig. 6, nos primeiros minutos do ensaio foi verificado um pico de aumento de temperatura em decorrência de processos exotérmicos de molhagem das partículas e de dissolução da alita [30]. Com o decorrer do processo de hidratação, e a consequente dissolução de íons, a solução foi saturada, diminuindo assim as taxas das reações, conforme observado pela diminuição da temperatura na Fig. 6. Este período, que apresentou uma baixa taxa de liberação

Tabela IV - ANOVA dos resultados da influência da adição do MNR no tempo de pega das pastas e do índice de consistência das argamassas.

[Table IV - ANOVA of the results of the influence of UOW addition on the setting time and the consistency index of the mortars.]

\begin{tabular}{cccccccc}
\hline Propriedade & SQ & GL & MQ & F & Valor p & Fc & Efeito significativo \\
\hline Início de pega & 1218,92 & 3 & 406,31 & 17,17 & 0,0008 & 4,07 & $\operatorname{Sim}$ \\
Fim de pega & 3419,33 & 3 & 1139,78 & 24,17 & 0,0002 & 4,07 & $\operatorname{Sim}$ \\
Índice de consistência (flow table) & 397,34 & 3 & 132,44 & 83,65 & 0,0000 & 4,07 & $\mathrm{Sim}$ \\
\hline
\end{tabular}

Nota: SQ - soma quadrada; GL - graus de liberdade; $M Q$ - média quadrada; $F$ - valor calculado de F; Valor $p$ - nível de significância; Fc - F crítico; se $p<5 \%$ e Fc $<$ F o valor é significativo, considerando o intervalo de confiança de $95 \%$. 
de calor e de reações, é conhecido como período de indução. Nas pastas de referência e com adições de 5\%, 10\% e 15\% de MNR, o período de indução foi de aproximadamente 2 h (Fig. 6). Com a precipitação da etringita, que ocorreu no período de indução, a quantidade de íons na solução foi reduzida. Quando a solução deixou de estar saturada, a alita começou a reagir de forma mais intensa com a água, formando C-S-H e portlandita, conforme observado na Fig. 6 pelo aumento de temperatura. Neste período, conhecido como período de aceleração, aconteceu o início e o fim de pega $[30,31]$. Foi possível notar que a temperatura máxima atingida no período de aceleração foi reduzida com a adição do MNR, indicando assim um retardo no processo de hidratação, também observado no ensaio de tempo de pega e provavelmente associado à presença de anidrita na composição do resíduo e, também, à redução gradativa da quantidade de cimento na mistura com a adição do resíduo. Após o pico principal de hidratação da alita, observouse um segundo pico de aumento de temperatura apenas para as misturas com $10 \%$ e $15 \%$ de MNR adicionado, provavelmente associado à formação de monossulfato. A formação deste segundo pico de liberação de calor aconteceu provavelmente devido à presença da anidrita na composição do resíduo (Fig. 4), que retardou a hidratação do $\mathrm{C}_{3} \mathrm{~A}$ e, por conseguinte, a formação de monossulfato [30].

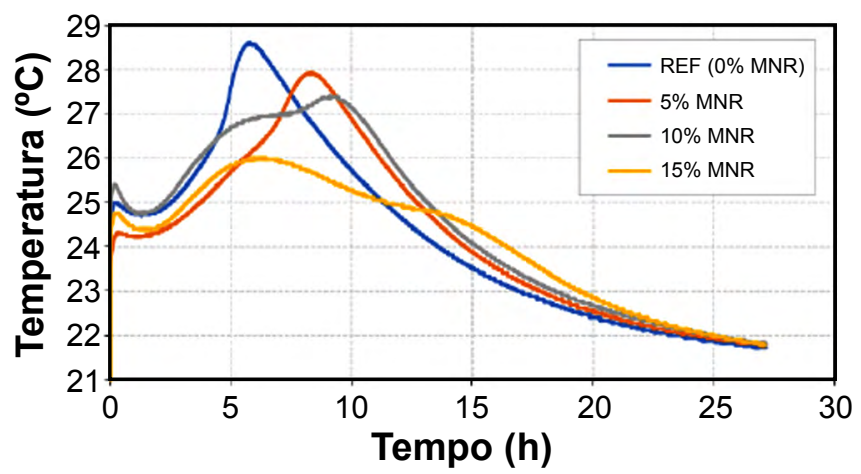

Figura 6: Evolução da temperatura das pastas de referência e com $5 \%, 10 \%$ e $15 \%$ de adição de MNR com o decorrer do processo de hidratação.

[Figure 6: Temperature evolution during the hydration process of the pastes with different UOW contents.]

Caracterização das argamassas no estado fresco: a Fig. 7 apresenta os resultados do índice de consistência das argamassas, obtidos por meio da mesa de consistência (flow table). Observou-se uma redução no índice de consistência com a incorporação de MNR. A argamassa de referência apresentou um índice de consistência de $248 \mathrm{~mm}$, enquanto as argamassas com 5\%,10\% e $15 \%$ apresentaram 244, 240 e $232 \mathrm{~mm}$, respectivamente. A redução do espalhamento em função do teor de MNR, apesar de pequena (cerca de 6\%), foi significativa conforme os dados apresentados na Tabela IV. O flow table é um método monoponto, ou seja, um método que mede o fluxo da matéria por meio de uma única taxa de cisalhamento e, por isso, é incapaz de caracterizar as argamassas de maneira completa, visto que os resultados obtidos através do flow table não dissociam a contribuição dos principais parâmetros reológicos, tais como viscosidade e taxa de cisalhamento [32]. Desta forma, os ensaios de reometria rotacional e squeeze flow foram realizados para melhor análise do comportamento reológico das pastas e argamassas contendo MNR.

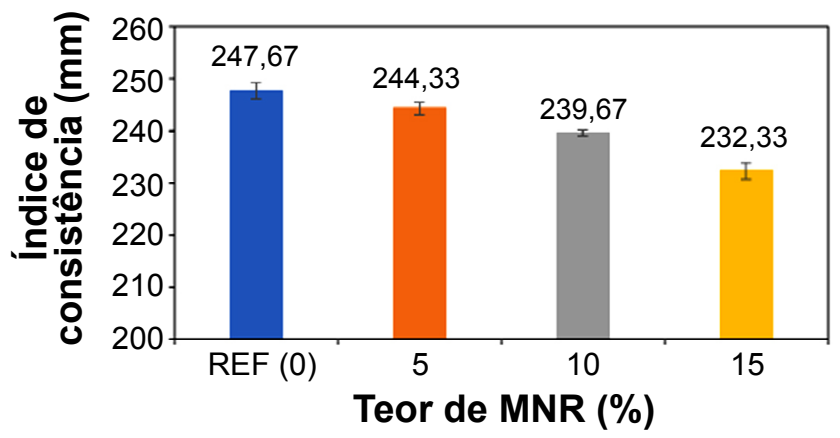

Figura 7: Índice de consistência das argamassas em função do teor de adição do MNR.

[Figure 7: Spread on flow table of the mortars as a function of the UOW content.]

Na Fig. 8 são apresentadas as curvas obtidas no ensaio de squeeze flow (carga em função do deslocamento) para as argamassas de referência e com teores de 5\%,10\% e $15 \%$ de MNR, $15 \mathrm{~min}$ após a mistura. Notou-se que o estágio I, referente ao regime de deformação elástica, foi bastante curto, imperceptível dentro da escala do gráfico. Os estágios II, referente à grandes deformações com baixo acréscimo de carga, e III, referente às pequenas deformações com grande acréscimo de carga, foram mais perceptíveis. Observa-se na Fig. 8 uma redução no deslocamento obtido ao final do ensaio com o aumento de adição de MNR, evidenciando assim que a adição do resíduo foi responsável por uma redução na plasticidade das argamassas. A adição do resíduo resultou na redução do estágio de deformação plástica e fluxo viscoso (estágio II) necessitando, assim, de maiores cargas para o mesmo deslocamento, o que gera dificuldades na aplicação da argamassa em obra [20].

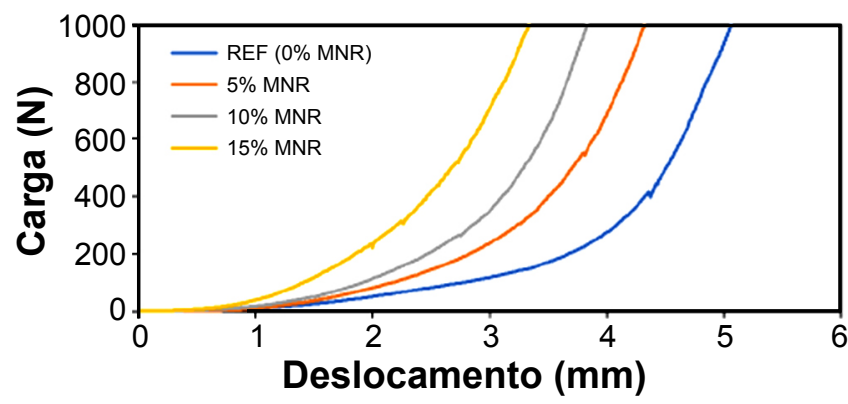

Figura 8: Curvas de carga em função do deslocamento obtidas por squeeze flow para as argamassas de referência e com teores de 5\%, $10 \%$ e $15 \%$ de MNR.

[Figure 8: Curves of load as a function of displacement obtained by squeeze flow for the reference mortar and mortars with the additions of $5 \%, 10 \%$ and $15 \%$ of UOW.] 
Na Fig. 9 são apresentadas as curvas provenientes do ensaio de reometria (torque em função do tempo) para diferentes teores de adição de MNR. Observou-se um aumento nos valores de torque com a adição de MNR. Esse resultado evidenciou o impacto negativo da adição de MNR na reologia das pastas cimentícias, que diminuiu a fluidez da mistura, elevando assim o torque monitorado no reômetro. A Tabela $\mathrm{V}$ apresenta a área de histerese e os parâmetros reológicos ao se aplicar o modelo de HerschelBulkley no primeiro ciclo de cisalhamento, aos 2 min de ensaio. Observaram-se aumentos no parâmetro de tensão de escoamento (a) e na viscosidade plástica $\left(\eta_{\mathrm{pl}}\right)$ com o aumento do teor de adição. Em relação ao índice de comportamento (c), a adição do MNR não influenciou significativamente e todas as pastas apresentaram comportamento pseudoplástico. A área de histerese é uma representação do trabalho realizado pela mistura e é proporcional à energia de mistura necessária para romper a estrutura dos aglomerados e homogeneizar a pasta [19]. Observou-se que o aumento do teor de MNR adicionado elevou a área de histerese, determinada no primeiro ciclo de cisalhamento. Desta forma, para se obter a mesma consistência da pasta de referência, é necessária uma maior energia de mistura e lançamento à medida que se adiciona MNR.

Os ensaios de flow table, squeeze flow e reometria rotacional evidenciaram a perda da plasticidade das pastas e argamassas com o aumento do teor de MNR adicionado. O comportamento observado foi devido, em parte, ao maior teor de partículas sólidas nas misturas e ao fato de

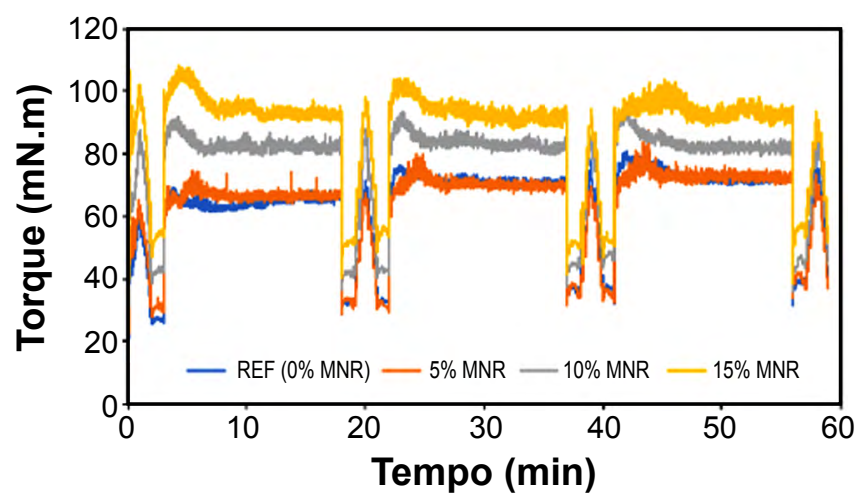

Figura 9: Curvas de torque em função do tempo, obtidas no ensaio de reometria rotacional, para diferentes teores de adição de MNR. [Figure 9: Curves of torque vs. time of the pastes with different UOW content.] as partículas do MNR atuarem como uma barreira ao escoamento do fluido ao seu redor, perturbando as linhas de fluxo, que deixaram de se apresentar como lâminas paralelas e passaram a se formar de maneira curvada, o que eleva a viscosidade da mistura [33]. Ademais, devido à elevada finura do resíduo, evidenciada nos resultados de área superficial específica Blaine (Tabela II) e granulometria (Fig. 3), uma parcela da água foi adsorvida pelas partículas do MNR, reduzindo assim a quantidade de água disponível para a argamassa [34]. Por fim, partículas finas apresentam uma tendência natural de se aglomerarem em meio aquoso, devido às forças capilares e de van der Waals [35]. Estes aglomerados são responsáveis por aumentar a viscosidade e a tensão de escoamento da argamassa, reduzindo assim a plasticidade da mistura $[35,36]$.

Caracterização das argamassas no estado endurecido: os resultados de porosidade e densidade aparentes das argamassas contendo diferentes teores de MNR, aos 28 dias de idade, estão apresentados nas Figs. 10a e 10b, respectivamente. Já a análise estatística pelo método ANOVA destes resultados é apresentada na Tabela VI. Observou-se que não houve variação estatisticamente significativa nos valores de porosidade e densidade aparentes com a adição de MNR. A adição do MNR, que possuiu partículas com tamanhos variados e uma área superficial Blaine próxima ao cimento, poderia promover um aumento da compacidade da argamassa, a partir de um melhor empacotamento de partículas e, assim, resultar em uma redução na porosidade. Em contrapartida, a perda de plasticidade com a adição do resíduo, observada nos ensaios de flow table, squeeze flow e reometria rotacional, gerou dificuldades na moldagem e adensamento, o que poderia ter resultado em um aumento na porosidade. Além disso, a redução no consumo de cimento também favorece uma redução da densidade e aumento de porosidade da matriz. Desta forma, com a ocorrência conjunta destes efeitos, não se observou uma diferença significativa na porosidade e densidade aparentes das argamassas.

Na Fig. 11 são apresentados os valores de módulo de elasticidade dinâmico obtidos para as argamassas estudadas e na Tabela VI são apresentados os resultados da análise estatística pelo método ANOVA. No cálculo do módulo de elasticidade dinâmico, considerou-se a velocidade de propagação ultrassônica nas amostras de argamassas. $\mathrm{O}$ tempo necessário para que o pulso ultrassônico atravesse a

Tabela V - Parâmetros reológicos obtidos pelo modelo de Herschel-Bulkley.

[Table V-Rheological parameters obtained by Herschel-Bulkley method.]

\begin{tabular}{ccccccc}
\hline \multirow{2}{*}{ Teor de MNR } & \multicolumn{3}{c}{ Parâmetro reológico } & $\begin{array}{c}\eta_{\mathrm{pl}} \\
\text { (mN.m.min) }\end{array}$ & Comportamento & $\begin{array}{c}\text { Área de histerese } \\
\text { (mN.min) }\end{array}$ \\
\hline $0 \%$ & 21,3 & 4,16 & 0,60 & 0,96 & Pseudoplástico & 88,27 \\
$5 \%$ & 26,4 & 3,42 & 0,44 & 1,10 & Pseudoplástico & 121,82 \\
$10 \%$ & 32,2 & 6,54 & 0,58 & 1,38 & Pseudoplástico & 189,65 \\
$15 \%$ & 34,8 & 11,50 & 0,48 & 1,67 & Pseudoplástico & 228,55 \\
\hline
\end{tabular}



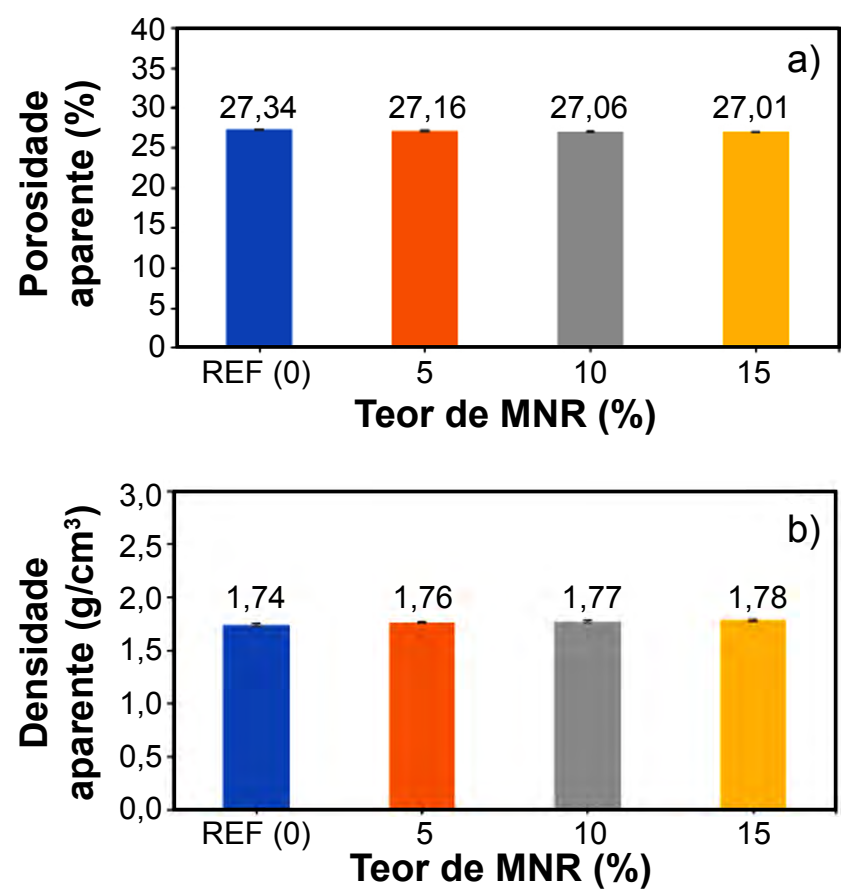

Figura 10: Porosidade (a) e densidade (b) aparentes das amostras de argamassa em função do teor de MNR aos 28 dias de idade.

[Figure 10: Apparent porosity(a) and density (b) of the mortars as a function of the UOW content at 28 days.]

amostra tem relação com os poros e/ou microfissuras, que desviam o caminho do pulso e diminuem a sua velocidade [37]. Então, uma maior velocidade de propagação ultrassônica resulta em um maior valor de módulo de elasticidade dinâmico, indicando assim um menor número de vazios e microfissuras e consequentemente maior resistência [38]. Conforme os dados apresentados na Tabela VI, não foram verificadas diferenças significativas no módulo de elasticidade em função do teor de MNR adicionado, corroborando com os resultados de densidade e porosidade aparentes apresentados na Fig. 10.

As Figs. 12a e 12b apresentam os resultados obtidos

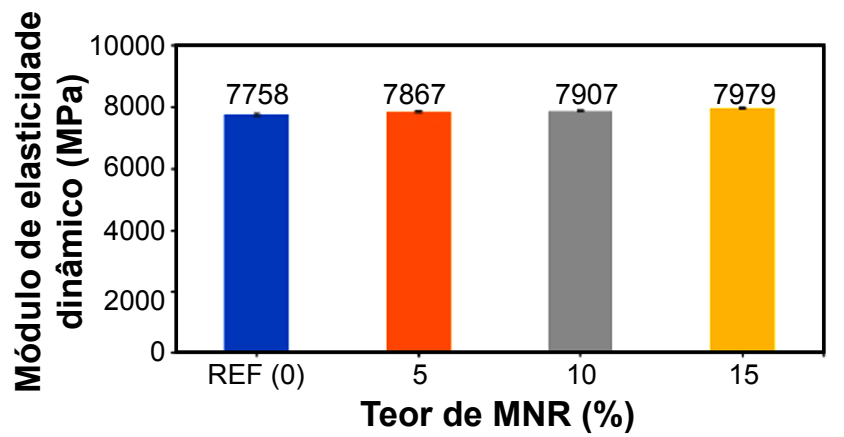

Figura 11: Módulo de elasticidade dinâmico das argamassas aos 28 dias em função do teor de MNR.

[Figure 11: Dynamic elastic modulus of the mortar, at 28 days as a function of the UOW content.]

nos ensaios de resistência à tração na flexão e à compressão axial, respectivamente, das argamassas com os diferentes teores de MNR, em função das idades dos corpos de prova ensaiados. Com base na análise estatística pelo método ANOVA, utilizando um nível de significância $(\alpha)$ de 0,05 (Tabela VI), observou-se que em geral a adição do resíduo nas misturas não promoveu mudanças significativas nas resistências à tração na flexão e à compressão axial, o que está de acordo com os resultados de densidade, porosidade e módulo de elasticidade dinâmico. Conforme discutido nos resultados de porosidade das argamassas, esse comportamento se deve à sobreposição do efeito fíler (favorável ao aumento da resistência mecânica) e da perda de trabalhabilidade e redução do teor de cimento (prejudiciais à resistência mecânica) com a adição de teores crescentes de MNR.

Caracterização das argamassas no estado aplicado: as resistências de aderência à tração das amostras de argamassas de referência e contendo MNR são apresentadas na Fig. 13 e a análise estatísticas destes resultados pelo método ANOVA é apresentada na Tabela VII. Observou-se que não houve variação significativa entre os resultados, estando todas as amostras de argamassas ligeiramente

Tabela VI - ANOVA dos resultados da influência da adição do MNR nas propriedades físico-mecânicas das argamassas. [Table VI - ANOVA of the results of the influence of UOW addition on the physical-mechanical properties of the mortars.]

\begin{tabular}{|c|c|c|c|c|c|c|c|c|}
\hline Propriedade & & SQ & GL & MQ & $\mathrm{F}$ & Valor $\mathrm{p}$ & $\mathrm{Fc}$ & Efeito significativo \\
\hline Densidade & & 0,00 & 3 & 0,00 & 2,41 & 0,1425 & 4,07 & Não \\
\hline Porosidade & & 0,27 & 3 & 0,09 & 1,56 & 0,2739 & 4,07 & Não \\
\hline $\begin{array}{c}\text { Módulo de } \\
\text { elasticidade dinâmico }\end{array}$ & & 77140 & 3 & 25713 & 0,85 & 0,5082 & 4,07 & Não \\
\hline \multirow{3}{*}{$\begin{array}{l}\text { Resistência à tração } \\
\text { na flexão }\end{array}$} & 3 dias & 2,66 & 3 & 0,89 & 3,59 & 0,0658 & 4,07 & Não \\
\hline & 7 dias & 8,57 & 3 & 2,85 & 38,37 & 0,0000 & 4,07 & Sim \\
\hline & 28 dias & 1,60 & 3 & 0,53 & 0,79 & 0,5333 & 4,07 & Não \\
\hline \multirow{3}{*}{$\begin{array}{l}\text { Resistência à } \\
\text { compressão axial }\end{array}$} & 3 dias & 3,40 & 3 & 1,13 & 1,26 & 0,3505 & 4,07 & Não \\
\hline & 7 dias & 4,37 & 3 & 1,46 & 2,62 & 0,1874 & 4,07 & Não \\
\hline & 28 dias & 5,71 & 3 & 1,90 & 1,55 & 0,2756 & 4,07 & Não \\
\hline
\end{tabular}



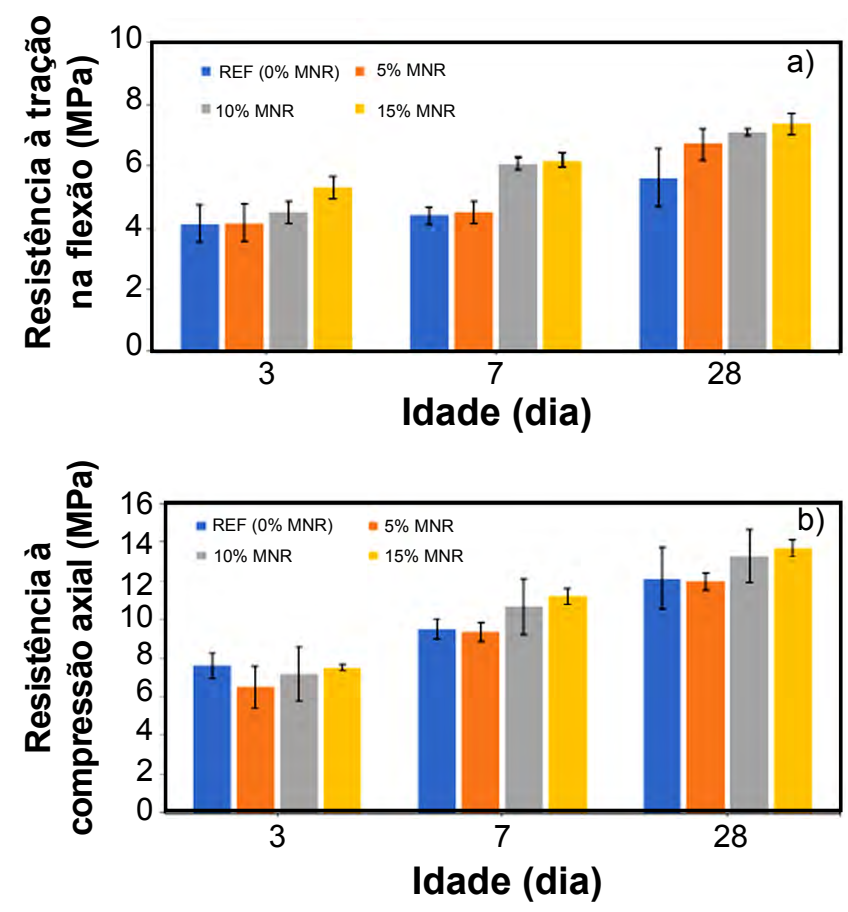

Figura 12: Resistências à tração na flexão (a) e à compressão axial (b) das argamassas com diferentes teores de adição de MNR em função do tempo.

[Figure 12: Flexural (a) and compressive (b) strengths of the mortars during the curing ages as a function of the UOW content.]

acima do valor ao exigido pela NBR 13528:2010 [29], que é $0,3 \mathrm{MPa}$ aos 28 dias. Assim, observou-se que o MNR não prejudica a aderência das argamassas de revestimento.

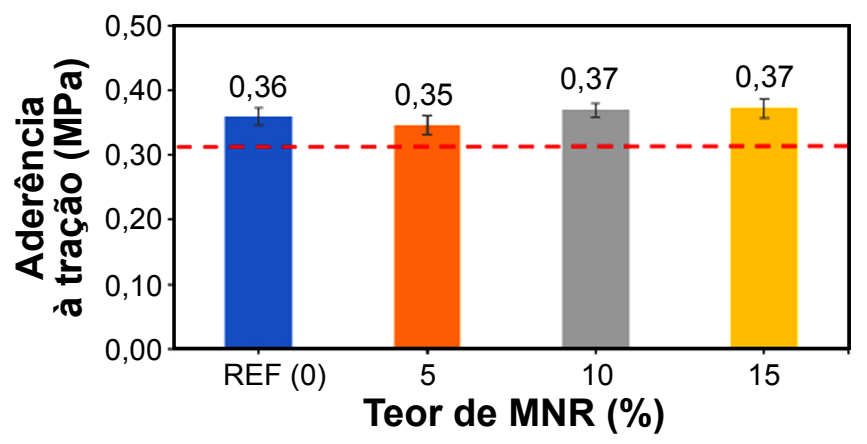

Figura 13: Resistência de aderência à tração das argamassas em função do teor de adição de MNR.

[Figure 13: Adhesion strength of mortars as function of the UOW content.]
A Fig. 14 apresenta, através dos resultados experimentais de absorção de água sob baixa pressão, a evolução da permeabilidade do revestimento obtida com o método do cachimbo (pipeta de Karsten) durante 60 min para as argamassas de referência e com adições de $5 \%, 10 \%$ e $15 \%$ de MNR. Os resultados mostraram que as argamassas de revestimentos de referência e contendo MNR apresentaram absorção de água inferior a $4 \mathrm{~mL}$ em 15 min, resultado considerado positivo para argamassas de revestimento [39], com variações que não foram estatisticamente significativas, de acordo com a análise ANOVA apresentada na Tabela VII, entre os diversos teores de adição, evidenciando que a presença do MNR não foi negativa para as principais propriedades das argamassas de revestimento. Assim como discutido para os resultados de densidade, porosidade e resistências à tração na flexão e à compressão axial, os resultados semelhantes encontrados no ensaio de absorção/permeabilidade pela pipeta de Karsten se deveram à sobreposição de diversos efeitos ao se incorporar o resíduo. O efeito fíler e melhor empacotamento de partículas com a adição do MNR, que possui partículas de diferentes tamanhos, favoreceu a redução da permeabilidade da argamassa. Contudo, a redução do consumo de cimento e a perda de plasticidade com a adição do resíduo geraram um efeito oposto, favorecendo um aumento na permeabilidade. Assim, de forma global, não foram observadas diferenças significativas na permeabilidade da argamassa com a adição do MNR.

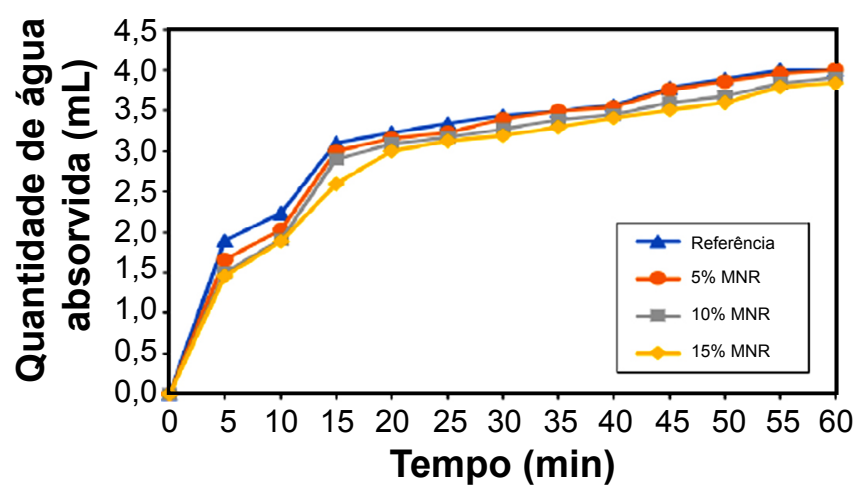

Figura 14: Absorção/permeabilidade à água das argamassas de referência e com adições de 5\%,10\% e $15 \%$ de MNR, pelo método do cachimbo (pipeta de Karsten).

[Figure 14: Water absorption of mortars with different content of UOW determined by Karsten tube technique.]

Tabela VII - ANOVA dos resultados da influência da adição do MNR nas propriedades do estado aplicado das argamassas. [Table VII - ANOVA of the results of the influence of UOW addition on the properties of applied state of the mortars.]

\begin{tabular}{cccccccc}
\hline Propriedade & $\mathrm{SQ}$ & $\mathrm{GL}$ & $\mathrm{MQ}$ & $\mathrm{F}$ & Valor $\mathrm{p}$ & $\mathrm{Fc}$ & Efeito significativo \\
\hline $\begin{array}{c}\text { Resistência de aderência à tração } \\
\begin{array}{c}\text { Absorção/permeabilidade à água } \\
\text { pela pipeta de Karsten }\end{array}\end{array}$ & 0,00 & 3 & 0,00 & 0,82 & 0,5166 & 4,07 & Não \\
& 0,00 & 2 & 0,00 & 0,53 & 0,3257 & 4,07 & Não \\
\hline
\end{tabular}




\section{CONCLUSÕES}

Os resultados obtidos no presente estudo indicaram que o minério não reagido (MNR) pode ser incorporado a matrizes cimentícias, apresentando resultados satisfatórios dentro dos requisitos normativos impostos para as argamassas de revestimento em relação às propriedades do estado fresco e às propriedades físico-mecânicas do estado endurecido. Contudo, para uma análise conclusiva sobre a viabilidade técnica da incorporação de MNR em argamassas de revestimento ressalta-se a necessidade de estudos complementares a respeito da lixiviação e solubilização destas argamassas, além do impacto da adição desse resíduo na durabilidade da argamassa. A partir dos resultados obtidos conclui-se que: i) a adição do MNR não influenciou significativamente as propriedades físicas e mecânicas das argamassas de revestimento; ii) a adição de MNR promoveu reduções significativas na plasticidade das argamassas devido à adição de partículas finas, no entanto este efeito pode ser reduzido e/ou eliminado com a correção da relação água/materiais secos e/ou utilização de aditivos superplastificantes; iii) foi evidenciado um pequeno retardo no início e fim de pega devido à adição do MNR, que foi explicado pela presença da anidrita $\left(\mathrm{CaSO}_{4}\right)$ na composição do resíduo; iv) em relação às propriedades no estado aplicado, a adição do MNR não influenciou significativamente a resistência de aderência à tração e a absorção/permeabilidade dos revestimentos; assim, concluiu-se que a adição de MNR não prejudicou nenhuma propriedade fundamental das argamassas de revestimento, podendo ser incorporado ao processo em substituição às matérias-primas naturais; v) a adição do MNR em argamassas de revestimento pode possibilitar a redução da ação impactante do crescimento tecnológico do MNR sobre o meio ambiente, sem abrir mão da qualidade do produto. Com o desenvolvimento de argamassas de revestimento a partir da incorporação do MNR, as matérias-primas naturais podem ser preservadas, acarretando na eliminação sustentável do resíduo, que pode passar a ser um subproduto.

\section{AGRADECIMENTOS}

Os autores agradecem à Coordenação de Aperfeiçoamento de Pessoal de Nível Superior (CAPES), ao Programa de Pós-Graduação em Engenharia Civil (PPEC), à Cristal Pigmentos do Brasil S.A., ao Laboratório de Caracterização de Materiais do IFBA pelas análises de FRX, e ao Laboratório de Materiais Cerâmicos (LACER) da UFRGS pelas análises granulométricas.

\section{REFERÊNCIAS}

[1] Ass. Bras. Empr. Tratam. Resíd., "Prefeituras perdem R\$ 600 milhões em arrecadação com destinação irregular de resíduos industriais, 2016", http://www.abetre.org.br, ac. 18/12/2018.

[2] C.A. Luz, M. Cheriaf, J. Rocha, in Proc. $4^{\circ}$ Sem. Des.
Sust. Recicl. Constr. Civil, Ibracon, S. Paulo (2001).

[3] D.V. Ribeiro, A.S. Silva, J.A. Labrincha, M.R. Morelli, Can. J. Civil Eng. 40 (2013) 557.

[4] D.M. Oliveira, T.N. Oliveira, A.C. Bezerra, V.J. Gomes, R.A. F Peixoto, in Anais $53^{\circ}$ Congr. Bras. Concret., Ibracon, Florianópolis (2011).

[5] N.T. Arruda Filho, C.P. Dantas, A.F. Leal, N.P. Barbosa, C.G. Silva, M.V. Alexandre, Rev. Bras. Eng. Agric. Ambient. 16, 8 (2012) 894.

[6] R.D. Mariano, D.V. Ribeiro, in Anais $57^{\circ}$ Congr. Bras. Concret., Bonito (2015).

[7] R.V. Silva, J. Brito, R.K. Dhir, Constr. Build. Mater. 105, 15 (2016) 400.

[8] D.D.M. Albuquerque, N.S. Amorim Júnior, V.S. Santos, D.V. Ribeiro, in Anais XII Simp. Bras. Tecnol. Argamas., S. Paulo (2017).

[9] T.R.S. Nobre, T.A. Santos, J. Alves, D.V. Ribeiro, in Anais VIII Enc. Cient. Fís. Apl., Vitória (2017).

[10] J.H. Potgieter, K.A. Horne, S.S. Potgieter, W. Wirth, Mater. Lett. 57 (2002) 157.

[11] B.B. Mariani, J.S. Andrade Neto, N.S. Amorim Júnior, D.V. Ribeiro, Amb. Constr. 19 (2019) 57.

[12] D.D.M. Albuquerque, J.S. Andrade Neto, N.S. Amorim Júnior, V.S. Santos, D.V. Ribeiro, Key Eng. Mater. 765 (2018) 319.

[13] NBR 10007, “Amostragem de resíduos sólidos”, Ass. Bras. Normas Técn., Rio Janeiro (2004).

[14] NBR NM 248, "Agregados - determinação da composição granulométrica”, Ass. Bras. Normas Técn., Rio Janeiro (2003).

[15] NBR 9776, “Agregados - determinação da massa específica de agregados miúdos por meio do frasco de Chapman - método de ensaio", Ass. Bras. Normas Técn., Rio Janeiro (1987).

[16] W.J. Santos, "Desenvolvimento de metodologia de dosagem de argamassas de revestimento e assentamento", Diss. Mestr., Un. Fed. Viçosa, Viçosa (2014).

[17] NBR 13276, “Argamassa para assentamento e revestimento de paredes e tetos - determinação do índice de consistência", Ass. Bras. Normas Técn., Rio Janeiro (2016). [18] NBR 16607, "Cimento Portland - determinação dos tempos de pega", Ass. Bras. Normas Técn., Rio Janeiro (2017).

[19] P.F.G. Banfill, Constr. Build. Mater. 8 (2005) 43.

[20] F.A. Cardoso, V.M. John, R.G. Pileggi, Cem. Concr. Res. 39 (2009) 748.

[21] NBR 15839, "Argamassa de assentamento e revestimento de paredes e tetos - caracterização reológica pelo método squeeze-flow", Ass. Bras. Normas Técn., Rio Janeiro (2010).

[22] F.G.S. Silva, H.M.C. Andrade, J.P. Gonçalves, Amb. Constr. 18 (2018) 343.

[23] H. Vikan, S. Jacobsen, "COIN project report 21", SINTEF Build. Infrastr., Oslo (2010).

[24] Z. Liu, J. Hong, J. Liu, in Proc. $2^{\text {nd }}$ Int. Conf. Sust. Constr. Mater., Wuhan (2012).

[25] J.S. Andrade Neto, V.S. Silva, in Anais XII Simp. Bras. 
Tecnol. Argamas., S. Paulo (2017).

[26] NBR 13279, “Argamassa para assentamento e revestimento de paredes e tetos - determinação da resistência à tração na flexão e à compressão", Ass. Bras. Normas Técn., Rio Janeiro (2005).

[27] NBR 9778, "Argamassa e concreto endurecidos determinação da absorção de água, índice de vazios e massa específica”, Ass. Bras. Normas Técn., Rio Janeiro (2005).

[28] NBR 15630, “Argamassa para assentamento e revestimento de paredes e tetos - determinação do módulo de elasticidade dinâmico através da propagação de onda ultra-sônica", Ass. Bras. Normas Técn., Rio Janeiro (2008). [29] NBR 13528, "Revestimento de paredes de argamassas inorgânicas - determinação da resistência de aderência à tração", Ass. Bras. Normas Técn., Rio Janeiro (2010).

[30] J.W. Bullard, H.M. Jennings, R.A. Livingston, A. Nonat, G.W. Scherer, J.S. Schweitzer, K.L. Scrivener, J.J. Thomas, Cem. Concr. Res. 41 (2011) 1208.

[31] K.L. Scrivener, P. Juilland, P.J.M. Monteiro, Cem.
Concr. Res. 78 (2015) 38.

[32] E.P. Koehler, D.W. Fowler, "ICAR report 105", Int. Center Aggreg. Res., Austin (2003).

[33] R.I. Oliveira, A.R. Studart, R.G. Pileggi, V.C. Pandolfelli, Dispersão e empacotamento de partículas: princípios e aplicações em processamento cerâmico, Fazendo Arte Ed., S. Paulo (2000) 195.

[34] M. Yang, H.M. Jennings, Adv. Cem. Based Mater. 2 (1995) 70.

[35] R.G. Pileggi, A.R. Studart, J. Gallo, V.C. Pandolfelli, Am. Ceram. Soc. Bull. 80 (2001) 27.

[36] A.L. Castro, J.B.L. Liborio, V.C. Pandolfelli, Cerâmica 57 (2011) 63.

[37] G. Skripkiūnas, D. Nagrockienè, G. Girskas, M. Vaicienè, E. Baranauskaitè, Proc. Eng. 57 (2013) 1045.

[38] Y. Benachour, C.A. Davy, F. Skoczylas, H. Houari, Cem. Concr. Res. 38 (2008) 727.

[39] L.A. Dias, H. Carasek, in Anais V Simp. Bras. Tecnol. Argamas., S. Paulo (2003) 519.

(Rec. 27/08/2018, Rev. 20/12/2018, Ac. 05/02/2019) 